\title{
Correction to: Risk factors associated with academic difficulty in an Australian regionally located medical school
}

Bunmi S. Malau-Aduli', Teresa O'Connor, Robin A. Ray, Yolanda van der Kruk, Michelle Bellingan and Peta-Ann Teague

\section{Correction}

Following publication of the original article [1], one of the authors reported that prior to publication her surname had changed from 'Kerlen' to 'van der Kruk', but that this change had not been incorporated in the final version.

The original article has been updated.

Received: 18 January 2018 Accepted: 18 January 2018

Published online: 12 February 2018

\section{Reference}

1. Bunmi S, Malau-Aduli, O'Connor T, Ray RA, van der Kruk Y, Bellingan M,

Teague P-A. Risk factors associated with academic difficulty in an Australian regionally located medical school. BMC Medical Education. 2017;17:266.

https://doi.org/10.1186/s12909-017-1095-9

* Correspondence: bunmi.malauaduli@jcu.edu.au

College of Medicine and Dentistry, James Cook University, QLD, Townsville,

Australia 